\title{
AVALIAÇÃ̄o do TRABALHO do PESSOAL AUXILIAR DE ENFERMAGEM REALIZADO EM UM CENTRO DE SAÚDE ESCOLA
}

\author{
Eliete Maria Silva* \\ Sônia Camila Sant'Anna** \\ Semíramis Melani de Melo Rocha***
}

\begin{abstract}
RESUMO - Entendemos a erifermagem como coletivo de várias categorias de trabalhadores envolvendo formaçōes diferentes. Dentro da típica divisão técnica do trabaIho, o gerenciamento e avaliação competem à enfermeira. Descrevemos a avaliação de desempenho dos auxiliares de enfermagem. Os funcionários participaram das atividades de avaliação desde a elaboração do roteiro até o início da análise dos dados. $\mathrm{Na}$ análise de avaliação de desempenho individual, distinguimos entre dados FORMAIS (referentes a racionalidade) dos NÄO FORMAIS (relativos a qualidade e relações no ambiente de trabalho). Também investigamos a avaliação da estrutura do serviço. Concluimos que esta descrição analítica contribui para o entendimento da avaliação de desempenho não como um fragmento mas como um processo. Esse processo deve partir de metas verificáveis qualitativa e quantitativamente.
\end{abstract}

ABSTRACT - We have understood Nursing as a collective of various kinds of professional activities involving different educational backgrounds. Within the typical technical division of labour management and assessment concern the nurse. We describe the performance assessment of nurse's aides. Nursing personal participated in the assessment activities from the design of the questionaire to the first draft of data analysis. In the analysis of individual performance assessment we make a distinction betweent "FORMAl" data (refering to racionality) to "NO FORMAL" (related to quality and relationship in the work environment). We also look at the assessment of the service structure. We conclude that this analytical description contributes to the inderstanding of performance assessment not as a fragment but as a process. This process should have both qualitative and quantitative verifiable goals.

\section{INTRODUÇÃO}

A idéia de estudar o processo de trabalho na enfermagem começa para nós a partir da percepção em nossa prática da desvalorização crescente do trabalho da enfermeira e do atuar em saúde. A nossa vivência em um Centro de Saúde - Escola (estabelecimento de atuação em ensino e pesquisa além da prestação de serviços à população), tem sido um importante estímulo para buscarmos compreender a crise da categoria de modo mais amplo.

Dentro da enfermagem, no final da década de setenta, acontece no XXXI Congresso Brasileiro de Enfermagem a reflexão sobre os temas: Enfermagem e Estrutura Social; Práticá de Enfermagem e Preparo e Aperfeiçoamento de Recursos Humanos. O tema oficial, elaborado por Maria Ivete de Oliveira iniciou a discussão da prática numa visão histórica-social. Outro trabalho de análise que pressupõe a inserção na estrutura econômica e social do país é o "Introdução às transformações na prática de enfermagem no Brasil, no período 1920 - 1978", realizado por docentes da Escola de Enfermagem de Ribeirão Preto - USP.

Em 1987 o XXXIX Congresso Brasileiro de Enfermagem tem como temática novamente o trabalho na enfermagem, vislumbrando seu significado historico e discutindo, entre outros temas, o processo e a divisão do trabalho na enfermagem.
Esta é uma visão da enfermagem que distancia do discurso idealizado, isto é, considera-a como trabalho, como uma atividade humana realizada, num dado tempo e espaço, por um grupo de pessoas que através deste reproduz sua existência humana, respondendo às suas necessidades ao mesmo tempo que possibilita a livre criação (ALMEIDA ${ }^{1}$; GERMANO ${ }^{5}$; $\mathrm{MELO}^{7}$; ROCHA $^{9}$; SILVA ${ }^{11}$ ).

O trabalho em saúde, conforme descrito por GONÇALVES ${ }^{6}$, reorganizou-se e desenvolveu-se nas scriedades capitalistas: "como forma de controlar a doença em escala social relativamente ampla e efetiva, como forma de recuperar a força de trabalho na mesma escala e finalmente, como forma de ampliar efetivamente os direitos e o consumo das classes subalternas".

A enfermagem moderna estruturou-se primeiramente na Inglaterra com Florence Nightingale, na segunda metade do século XIX. Constituiu-se em profissão de apoio ao trabalho médico, com intuito de controlar o ambiente para maior êxito do cuidado médico e restabelecimento do doente. Difundiu-se assim para outros países da Europa e Américas.

No Brasil, a enfermagem acontece enquanto prática institucionalizada a partir da década de vinte sob a concepção norte-americana. Dessa época em diante

* Auxiliar de Ensino da Escola de Enfermagem de Ribeirão Preto - U.S.P.

** Enfermeira do Centro de Saúde Escola de Ribeirão Preto - U.S.P.

*** Professora Assist. Doutor da Escola de Enfermagem de Ribeiräo Preto - U.S.P. 
passa, como integrante do setor saúde, por transformaçōes de seu saber e de sua prática. (ALMEIDA' ${ }^{1}$ ).

Antes de abordar a divisão do trabalho na enfermagem, vejamos o significado do processo de trabalho e a divisão social sob o ponto de vista dialético: o trabalho é um processo que envolve uma atividade mental de concepção e uma atividade manual de confecção e execução dessa idéia. Segundo Mark e Engels citados por BRAVERMAN ${ }^{3}$, a divisão social do trabalho se dá livremente entre os homens e os divide na sociedade em grupos, desde os tempos mais remotos.

A divisão social do trabalho se dá entre os sexos, entre a agricultura e a indústria, entre o artesão e o ferreiro. A primeira forma de propriedade é a tribo, forma rudimentar de produção. A segunda forma é a propriedade comunitária e a propriedade estatal, que surge da união de várias tribos. A terceira forma é a feudal, caracterizada pelo servo de um lado e o senhor de outro, apoiado na posse da terra.

Esse mesmo autor comenta que a divisão social do trabalho fortalece o homem e permite a própria sobrevivência da espécie. A divisão social não retira do homem a concepção do trabalho, enquanto que o que ocorre com a divisão técnica do trabalho tem importância e consequências bastante distintas. Nessa mesma linha ele cita que: "A divisão técnica do trabalho é a subdivisão da tarefa. Uma única atividade é dividida e feita por vários indivíduos, isto leva a uma distância da concepção global da atividade".

A divisão técnica se dá na emergência do capitalismo mais especificamente no período manufatureiro, século XVI e XVII, onde os princípios de racionalidade e produtividade norteiam as relaçốes de trabalho, justificada pela possibilidade de se produzir mais, em menor tempo, com o menor gasto. (BRAVERMAN ${ }^{3}$ ).

O setor saúde, apesar de não produzir "mercadorias" e sim prestar serviços, é regido por estes mesmos princípios de racionalidade e produtividade: no atuar em saúde que se toma parcelado, subdividido se denuncia a divisão técnica do trabalho. $\mathrm{Na}$ enfermagem, as tarefas de supervisão e controle estão sob responsabilidade do enfermeiro, ficando as atividades de cuidado direto do paciente como atribuição dos técnicos, auxiliares, visitadores sanitários e atendentes de enfermagem $\left(\mathrm{MELO}^{7}\right)$.

A enfermagem é heterogênea tanto na formação profissional quanto na constituição numérica, para melhor ilustrar citamos dados de pesquisa do COFEn / $\mathrm{ABEn}^{4}$ que mostram: enfermeiros 25.889 (8.5\%), técnicos 19.935 (6.6\%), auxiliares $64.288(21.1 \%) \mathrm{e}$ $194.174(63.5 \%)$ atendentes. Embora os atendentes recebam a mais precária formação, constituem o maior número e assumem a maior parcela do cuidado direto.

Não queremos simplesmente polemizar acerca de que o enfermeiro deva realizar o cuidado direto. Nossa constatação é que o exigido do profissional nas instituições é a tarefa de supervisão e gerenciamento para a qual também não está devidamente preparado.

Recapitulando o que vinhamos colocando anteriormente como situação problema: percebemos a enfermagem como um trabalho coletivo e associado de várias categorias de trabalhadores com formação e atribuições funcionais diversas, tendo como característica a divisão técnica do trabalho onde o enfermeiro é prioritariamente administrador-gerente e o auxiliar prestador de cuidados diretos.
A atividade gerencial consiste prioritariamente em controlar o serviço, bem como ef etuar avaliações deste quanto à racionalidade, produtividade e qualidade da assistência de enfermagem.

Foi a partir da discussão da qualidade de desempenho, da necessidade de sistematização das atividades das enfermeiras do C.S.E. (a supervisão e avaliação de desempenho não eram sistematizadas) que tomou corpo a idéia deste estudo e, à medida que as sistematizávamos, percebemos a relação com a teoria da divisão do trabalho de Braverman.

Em outras palavras, altear a qualidade da assistência, a nosso ver, demandava avaliações contínuas e sistematizadas, o fazer estas avaliações levou-nos a questionar: como avaliar essas atividades se cada pessoa fazia somente uma parte, se as tarefas são todas parceladas?

Outra questão de orientação em nosso estudo é a de que os Programas da Secretaria de Estado da Saúde de São Paulo se estruturaram com normas e procedimentos nos moldes da Administração Clássica de Taylor e Fayol, citados por ROCHA ${ }^{\circ}$. Tais princípios preconizam justamente a divisão técnica do trabalho.

Nosso problema consistia em avaliar o desempenho do pessoal auxiliar de enfermagem em uma instituição de saúde. Realizada a avaliação buscamos o referencial teórico em Bravermam, acerca da divisão técnica do trabalho.

Passamos, então, a especificar o objetivo deste trabalho: - descrever a avaliação de desempenho dos técnicos, auxiliares, atendentes e visitadores sanitários de um Centro de Saúde Escola.

\section{METODOLOGIA}

\subsection{Descrição da Unidade}

O Centro de Saúde Escola (CSE) de Ribeirão Preto, local de desenvolvimento deste trabalho, é gerido por Convênio da Faculdade de Medicina de Ribeirão Preto com a Secretaria de Estado da Saúde. Está inserido no Sistema Unificado e descentralizado de Saúde (SUDS), Distrito Sanitário III (D.S.III), atendendo, à noroeste do município, uma população estimada em 126.000 habitantes, calculada em trinta por cento ( $30 \%$ ) da população de Ribeirão Preto, numa extensão de $41,05 \mathrm{Km}^{2}$.

Nosso estudo desenvolveu-se na unidade-sede administrativa do CSE, situada à Rua Cuiabá, no 601, bairro Sumarezinho, que funciona a nível de assistência primária e secundária.

A nível primário conta com programas de assistência integral à saúde da criança, mulher e adulto, para atendimento da população adscrita ao Sumarezinho.

A nível secundário é "unidade de referência" para toda a região do D.S. III e vários são os programas: controle da hanseníase, tuberculose, hipertensâo arterial, diabetes, anemias e doenças respiratórias da infância. Além dos especialistas pertinentes a esses programas contam ainda com médicos psiquiatra, oftalmologista e infectologista e outros profissionais: odontologos, fisioterapeuta, assistente social e psicбlogas. Todo o serviço administrativo e de vigiláncia epidemiologica da área sedia-se nessa unidade.

$O$ serviço de enfermagem dessa unidade conta 
com duas enfermeiras, uma graduanda em efermagem, 10 (dez) técnicos de enfermagem, 07 (sete) auxiliares de enfermagem, 6 (seis) atendentes e uma visitadora sanitária. Os profissionais de nível superior completo são Técnicos Operacionais Superiores, segundo estruturação da Carreira da Universidade de São Paulo (USP) e atuam: uma na coordenação do Serviço de Vigilância Epidemiológica e outra na Coordenação do Serviço de Enfermagem da referida unidade. Os demais são Técnicos Operacionais Médios, sendo que desempenham atividades de menor ou maior complexidade em função de formação anterior e, principalmente, de experiência o treinamento em serviço (QUADRO 1).

$\mathrm{O}$ serviço de enfermagem está subordinado à Coordenação da Equipe Técnica de Apoio que está diretamente ligada à Direção Técnica do CSE, esta última é exercida por um docente do Departamento de Medi- cina Social da FMRP - USP, e a primeira pela Assistente Social do Convênio.

A estruturação deste quadro de pessoal é bastante recente, sendo que a maioria das contratações datam de menos de três anos.

A seleção e contratação de pessoal era atribuição do Convênio, o que ao mesmo tempo que trazia autonomia acarretava também grande responsabilidade aos profissionais já contratados que assumiam essa atividade.

Foi da necessidade de estruturar e formalizar a avaliação do tempo de experiência (três meses) após contratação que primeiro surgiu a discussão de avaliação de desempenho. Nessa época batalhava-se pela incorporação do pessoal do Convênio ao quadro da Universidade e antes mesmo que essa se desse em setembro de 1988 foram realizadas avaliações de todos os funcionários para enquadramento na carreira.

QUADRO 1: Pessoal de Enfermagem do Centro de Saúde Escola (unidade Cuiabá), segundo víncalo empregatício e formação escolar set./1988.

\begin{tabular}{|c|c|c|}
\hline \multirow{2}{*}{ FORMAÇĀO } & \multicolumn{2}{|c|}{ VINCULO EMPREGATICIO } \\
\hline & U.S.P. & S.E.S. \\
\hline $\begin{array}{l}\text { Enfermeira superior completo } \\
\text { superior incompleto } \\
\text { Técnica de Enfermagem } 2^{\circ} \text { grau completo } \\
\text { Auxiliar de Enfermagem } 2^{\circ} \text { - grau completo } \\
\text { Atendente } 1 \text { ou } 2^{\mathbf{0}} \text { grau } \\
\text { Visitador Sanitário } 2-\text { grau }\end{array}$ & $\begin{array}{l}02 \text { T.O.S. } \\
01 \text { T.O.M. } \\
10 \text { T.O.M. } \\
07 \text { T.O.M. } \\
04 \text { T.O.M. }\end{array}$ & $\begin{array}{l}01 \text { vis. san. } \\
01 \text { vis. san. } \\
01 \text { vis. san. }\end{array}$ \\
\hline TOTAL & 24 & 03 \\
\hline
\end{tabular}

Legenda : U.S.P. - Universidade de São Paulo

S.E.S. - Secretaria Estadual da Saúde

T.O.S. - Técnica Operacional Superior

T.O.M. - Técnico Operacional Médio

vis. san. - Visitador Sanitário.

\subsection{Coleta dos Dados empíricos}

\section{a) Instrumento de Coleta}

Durante o segundo semestre de 1988 iniciou-se um trabalho de avaliação sistemática do pessoal auxiliar de enfermagem. $O$ serviço dispunha de um roteiro elaborado por seis funcionários de nível médio do Serviço de Enfermagem e uma das enfermeiras, a partir de critérios adotados durante o processo seletivo e dos ítens de avaliação da Comissão Central da Avaliação - USP (complexidade da atividade, competência e grau de instrução).

Esse roteiro foi apresentado e discutido em reu'nião do serviço de enfermagem, agendada específi-. camente para tratar do tema Avaliação; não sofreu modificação e foi utilizado nas auto-avaliações e nas entrevistas. A última questão do roteiro foi acrescido por recomendaçāo da coordenadora da equipe técnica de apoio. (ANEXO 1)

\section{b) Pessoal de Enfermagem Avaliado}

Dada a peculiaridade da instituição que incentivava a participação dos funcionários na organização do serviço, optamos pela atuação conjunta com estes durante todo o processo de avaliação.

Foram avaliados todos os funcionários constantes do QUADRO 1 com exceção das enfermeiras graduadas. São 22 (vinte e dois) funcionários da U.S.P. e 03 (três) da S.E.S., perfazendo um total de 25 (vinte e cinco) funcionários.

\section{c) Procedimento de Coleta}

A partir desta reunião marcamos entrevistas individuais dos funcionários com uma enfermeira do serviço e uma enfermeira-docente da EERP - USP que até julho de 1988 fazia parte do quadro de enfermeiras do C.S.E.. Prevíamos que antes da entrevista o funcionário deveria, baseado em reflexão pessoal, apresentar sua avaliação por escrito, segundo o roteiro. $O$ tempo entre a reuniẫo e a primeira entrevista foi de uma semana, sendo que os funcionários tiveram o tempo que necessitassem para entrega do roteiro escrito já que o agendamento da entrevista se fazia a partir de suas disponibilidades (às tardes, em dois dias por semana).

Para escrever a avaliação permitiu-se consulta livre entre os funcionários e também com as enfermeiras. A prática de avaliação não era rotineira e vivenciamos certo tumulto nas relações de trabalho, sendo que algumas pessoas mostravam se sentir "ameaçadas" pela proposta, o que no efetivar-se das entrevistas parecia se diluir, ao menos em parte.

As entrevistas transcorreram no período de doze de setembro a vinte e oito de outubro de 1988 , sendo que sete dos vinte e cinco funcionários tiveram dois momentos de encontro por necessidade de revisão de seu material escrito (falta de clareza, coerência etc.) ou por exiguidade do tempo para os tantos pontos que mereciam abordagem; esse tempo havia sido plane jado em trinta minutos, o que para dezoito pessoas foi suficiente. 
Sempre que as anotações de auto-avaliação foram entregues antes da entrevista, as entrevistadoras estudavam os pontos que pareciam demandar maior ressalva ou esclarecimento, ocorrendo assim certa organização acerca da forma da condução e dos temas a serem abordados.

\section{d) Categorização dos Dados}

Durante o processo de análise verificamos que alguns ítens poderiam ser agrupados em FORMAIS pois, se referem à forma, como se dá o processo de trabalho, isto e, a racionalidade, econômica de tempo e movimento, uso de técnicas, uniforme. Outros ítens em NÄO FORMAIS se relacionam à concepção, percepção do processo de trabalho, relações pessoais entre funcionários e clientela, criatividade, qualidade.

Não consideramos que esta dicotomía seja ef etiva no concreto do trabalho contudo dada a ênfase burocrática e normativa dos serviços de saúde observamos que os ítens FORMAIS eram abordados de maneira distintas daqueles NÄO FORMAIS.

$\mathrm{O}$ instrumento permitiu respostas abertas, as quais foram categorizādas quanto ao conteúdo em:

- não identificou problema(s): o funcionário não registrou dificuldades em relação ao ítem mencionado;

- não mencionou o ítem: o funcionário não contemplou o ítem na avaliação escrita; e

- identificou problema(s): o funcionário citou e/ou especificou a dificuldade ou problema percebido.

Das 32 (trinta e duas) entrevistas e 20 (vinte) anotações temos inúmeros dados a serem trabalhados no cotidiano da assistência e da supervisão que, ao mesmo tempo, carecem de melhor sistematização e análise o que pretendemos desenvolver a seguir.

\section{APRESENTACÃO E DISCUSSÃO DOS DADOS EMPÍRICOS Dados FORMAIS}

Incluindo aqui os ítens: registro (de atividade e reuniões), aparência pessoă (uniforme, avental, luvas), frequência e pontualidade, desempenho técnico (somente enquanto técnicas e instrumentos) e organização (de material, do processo de trabalho e tempo).

TABELA I: Námero e freqũencia de respostas aos f́tens FORMAIS da Avaliação do Pessoal Auxiliar de Enfermagem C.S.E. - Cuiabá. Ribeirão Preto, 1988 (I = 20)

\begin{tabular}{|c|c|c|c|c|c|c|}
\hline \multirow[t]{2}{*}{ Itens } & \multicolumn{2}{|c|}{$\begin{array}{l}\text { Não identifica } \\
\text { problemas }\end{array}$} & \multicolumn{2}{|c|}{$\begin{array}{c}\text { Não menciona } \\
\text { o item }\end{array}$} & \multicolumn{2}{|c|}{$\begin{array}{l}\text { Identifica } \\
\text { problemas }\end{array}$} \\
\hline & $n^{\circ}$ & $\%$ & $\mathrm{n}^{\circ}$ & $\%$ & $\mathrm{n}^{-}$ & $\%$ \\
\hline $\begin{array}{l}\text { Registro } \\
\text { atividades } \\
\text { reuniões } \\
\text { Aparência pessoal } \\
\text { Desempenho técnico } \\
\text { qualitativo } \\
\text { quantitativo } \\
\text { Organização } \\
\text { método } \\
\text { tempo } \\
\text { material } \\
\text { freqũericia e } \\
\text { pontualidade }\end{array}$ & $\begin{array}{l}10 \\
05 \\
04 \\
11 \\
09 \\
12 \\
11 \\
06 \\
16 \\
14\end{array}$ & $\begin{array}{l}(50) \\
(25) \\
(20) \\
(55) \\
(45) \\
(60) \\
(55) \\
(30) \\
(80) \\
(70)\end{array}$ & $\begin{array}{l}02 \\
10 \\
02 \\
02 \\
06 \\
06 \\
07 \\
06 \\
03 \\
03\end{array}$ & $\begin{array}{l}(10) \\
(50) \\
(10) \\
(10) \\
(30) \\
(30) \\
(35) \\
(30) \\
(15) \\
(15)\end{array}$ & $\begin{array}{l}08 \\
05 \\
14 \\
07 \\
05 \\
\\
02 \\
02 \\
08 \\
01 \\
03\end{array}$ & $\begin{array}{l}(40) \\
(25) \\
(70) \\
(35) \\
(25) \\
(10) \\
(10) \\
(40) \\
(05) \\
(15)\end{array}$ \\
\hline
\end{tabular}

Considerando a TABELA I observamos que: $70 \%$ percebe problemas em relação a aparência pessoal ressaltando a necessidade de vestimenta adequada quer para identificação ou para proteção pessoal ao mesmo tempo que a maioria não identifica problema quanto ao desempenho técnico qualitativo (55\%) e organização de método de trabalho (60\%). Vale ressaltar que o uso de uniforme como parte do desempenho qualitativo foi pouco discutido e valorizado em períodos anteriores a este trabalho.

Outro ponto de contradição parece-nos ser que $50 \%$ das pessoas não menciona o ítem registro de reuniões numa instituição que realiza frequentemente reuniões e discussões, sugerindo que estas não percebidas como atividade de trabalho.
Em relação a organização os problemas se relacionam a falta de material; as pessoas colocam-se como pontuais e frequentes ao trabalho, se atrasando por probiemas concretos com transporte e filhos.

Como outro ponto relevante fez-se menção à falta de parâmetros para avaliação do desempenho técnico quantitativo.

\section{Dados NÃO FORMAIS}

Agrupamos os itens: disponibilidade, iniciativa em relação às próprias atividades e à aprendizagem, entrosamento com funcionários, pacientes, alunos e residentes, cooperação no trabalho como um todo, em relação aos colegas e aos pacientes. 
TABELA II - Námero e freqüência de respostas aos itens NAO FORMAIS da Avaliação do Pessoal Auxiliar de Enfermagem C.S.E. - Cuiabá. Ribeirão Preto, 1988. (n= 20).

\begin{tabular}{|c|c|c|c|c|c|c|}
\hline \multirow{2}{*}{ Itens } & \multicolumn{2}{|c|}{$\begin{array}{l}\text { Não Identifica } \\
\text { problemas }\end{array}$} & \multicolumn{2}{|c|}{$\begin{array}{c}\text { Não Menciona } \\
\text { o item }\end{array}$} & \multicolumn{2}{|c|}{$\begin{array}{l}\text { Identifica } \\
\text { problemas }\end{array}$} \\
\hline & $\mathrm{n}^{\mathrm{o}}$ & $\%$ & $\mathrm{n}^{\circ}$ & $\%$ & $\mathrm{n}^{0}$ & $\%$ \\
\hline Disponibilidades & & & 02 & (10) & 03 & $(15)$ \\
\hline $\begin{array}{l}\text { miciativa de } \\
\text { atividades } \\
\text { apredizagem }\end{array}$ & $\begin{array}{l}16 \\
13 \\
14\end{array}$ & $\begin{array}{l}(80) \\
(65)\end{array}$ & $\begin{array}{l}03 \\
04 \\
02\end{array}$ & $\begin{array}{l}(15) \\
(20)\end{array}$ & $\begin{array}{l}01 \\
03 \\
04\end{array}$ & $\begin{array}{l}(05) \\
(15)\end{array}$ \\
\hline $\begin{array}{l}\text { Cooperação com } \\
\text { colegas } \\
\text { pacientes }\end{array}$ & $\begin{array}{l}14 \\
10 \\
15\end{array}$ & $\begin{array}{l}(10) \\
(50) \\
(75)\end{array}$ & $\begin{array}{l}02 \\
03 \\
04\end{array}$ & $\begin{array}{l}\text { (10) } \\
\text { (15) }\end{array}$ & $\begin{array}{l}04 \\
07 \\
01\end{array}$ & $\begin{array}{l}(20) \\
(35) \\
(05)\end{array}$ \\
\hline
\end{tabular}

Na TABELA II a grande maioria das pessoas não identificou problemas, ressaltando apenas no ítem cooperação alguma dificuldade sem entendê-la de forma dinâmica - ajudar e ser ajudado - sendo percebida a disponibilidade para ajudar acompanhada, contudo, pela dificuldade em pedir ajuda, des!ocando o problema para o outro que "não of erece ajuda".

Embora a maioria $(75 \%)$ se coloca disponível durante a jornada integral de trabalho, é relatado ociosidade de tempo que se contradiz com a avaliação de grande iniciativa para as atividades $(80 \%)$ e para a aprendizagem $(65 \%)$.

$\mathrm{Na}$ avaliação individual do entrosamento $70 \%$ dos documentos refere não identificar problemas.

Observamos que os ítens referentes à forma são mais rigorosamente avaliados que os ítens referentes ao conteúdo; outra análise é que a avaliação individual É mais positiva que a avaliação da estrutura do serviço ou mesmo de seus colegas de trabalho, como se o trabalhador $s \sigma$ pudesse objetivar as suas possíveis dificuldades quando observa o geral : a grande maioria se diz individualmente disponível e coloca que "os outros são acomodados".

\section{Avaliação da estrutura do serviço}

Passemos aos ítens de avaliação da estrutura de serviço, sugestōes, metas e objetivos de trabalho. Nestes ítens nẫo procedemos a divisão entre FORMAIS e NÂO FORMAIS pois, entendemos que aqui eles se entrelaçam de maneira mais complexa. É importante registrar que este entrelaçamento existe desde o início mas preferimos, para efeito de entendimento, fazer a divisẫo inicial.

Das respostas à Avaliação da Estrutura temos que 03 (três) pessoas não mencionaram o item, uma não identifica problemas pois, considera que com a volta da jornada de oito horas e contratação de novos profissionais somada a chegada de novos materiais e construção/ativação de novas salas a estrutura "está melhorando".

Então, temos 16 (dezesseis) avaliações com identificação de problemas : destes 05 (cinco, 25\%) mencionam somente problemas de ordem material, 03 (três, 15\%) problemas relativos somente aos recursos humanos e 08 (oito, $40 \%$ ) avaliam que existem problemas de recursos humanos e materiais (FIGURA 1).

\section{FIGURA 1: Freqũência de funcionários que identificou problemas relacionados aos RECURSOS HUMANOS E MATERIAIS.}

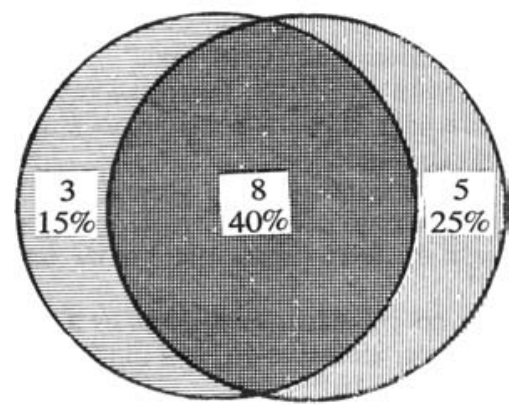

RECURSOS HUMANOS

RECURSOS MATERIAIS

RECURSOS HUMANOS E MATERIAIS 


\section{ANEXO 1}

\section{ROTEIRO}

\section{AVALIAÇÃO}

a. iniciativa em relação às próprias atividades e à aprendizagem

b. cooperação no trabalho como um todo, em relação aos colegas e aos pacientes

c. desempenho técnico (qualitativo e quantitativo)

d. registro das atividades (atendimento, reunião etc.), boletins, fichas, gráficas

e. entrosamento com funcionários, pacientes, alunos, residentes luvas)

f. freqüência, pontualidade

g. aparência pessoal (uso e condições de avental,

h. disponibilidade

i. organização : método de trabalho material de trabalho tempo das atividades

\section{AVALIAÇÃO DA ESTRUTURA DO SERVIÇO}

a. Recursos humanos

b. Recursos materiais

\section{METAS}

em relação às deficiências percebidas na avaliação

\section{SUGESTÕES}

em relação à estrutura do serviço

\section{METAS GERAIS}

Conhecimento das METAS GERAIS da Unidade e do Centro de Saúde e ESPECÍfICAS da área de trabalho.

ANEXO 2

\section{CITAÇÕES DAS RESPOSTAS DOS FUNCIONÁRIOS AOS ITTENS DO ROTEIRO REGISTRO}

\section{REGISTRO}

“Às vezes não registro reuniōes por impossibilidade auditiva, mas, sempre que possível gosto de fazê-lo".

"Talvez alguns registros de fatos acontecidos ou atendimentos de enfermagem feitos por mim há alguns meses atrás, tenham se perdido, mas à partir do momento que iniciei trabalho de grupo, adquirir o hábito de registrar todos os dados e estes são arquivados no prontuário do paciente, ou arquivados na pasta $\mathrm{A}-\mathrm{Z}$. Quanto às reuniões não adquiri o hábito de ir para a mesma com papel e caneta para anotar".

"não tenho dificuldades em fazer boletins, fichas, gráficos, mas esqueço muito de registrar os atendimentos que faço na porta e eventuais, que agora estou procurando por em prática, pois sei a importância de uma anotação".

"Reuniōes - deveria ter sempre, mas, muito mais organizada do que é hoje. Acho que todos funcionários deveriam abedecer e respeitar o horário marcado".

"deveria ter mais e mais frequentes, porque só assim poderiamos resolver os problemas que já temos e os que poderão vir a ter".

"Por vezes é possível a mim marcar no prontuário o fornecimento da medicação e as anotações gerais isso em dia de menor movimento, porém na maioria dos dias não há realmente condições de buscar a pasta de um paciente enquanto outros esperam sua vez e a marcaçấo não é feita como realmente deveria ser na teoria pois na prática a realidade por vezes $\varepsilon$ outra e temos que nos adaptar a ela, marcando só nas costas do cartão e na receita médica o que foi fornecido e quando foi, apesar de saber que isso não é o procedimento ideal".

"Quanto ao registro das atividades, nem sempre temos oportunidade de poder colocar no papel o que fazemos na verdade. Pois se fazemos um atendimento bem feito, nem sempre nos sobra tempo para colocar no papel".

\section{APARÊNCIA PESSOAL}

"nem sempre é muito boa em vestimentas por impossibilidades financeiras. Procuro cuidar sempre da higiene corporal e não usar roupas inadequadas. Seria muito bom se houvesse um uniforme."

"Sou a favor do uso do uniforme (avental) para sermos melhor identificados pelas pessoas que procuram o Centro de Saúde".

"Acho importante o uso de avental, de luvas para a pessoa que está em contato direto com o paciente, porque apesar de tudo temos que cuidar também da nossa saúde".

"Quanto no vestuário acho simples a maneira de todos se vestirem, inclusive eu, sou indiferente ao uso de uniforme ou avental".

"não sou a favor do uso de aventais que são sempre usados abertos e para mim sua eficiência quanto à proteção é bastante discutível".

(sugere adoção de uniforme) 
As METAS em relação às deficiências percebidas na avaliação foram bastante individualizadas e com referência aos ítens Formais da primeira parte da avaliação, apresentando um forte caráter de intencionalidade do funcionário no sentido de atingir uma "boa conduta". Em outras palavras, os funcionários se propõem a melhorarem o desempenho ou a estarem mais vigilantes para não errarem.

Possivelmante as respostas foram induzidas, durante o processo de avaliação pelas entrevistadoras, através da forma de avaliar e do roteiro. O problema, inicialmente colocado deixa claro que o propósito das enfermeiras, enquanto responsáveis pelo controle do processo de trabalho, $\in$ manter a racionalidade e produtividade do serviço, daí a necessidade de avaliação.

Quanto as SUGESTÕES também são em sua maioria individuais e referem-se predominantemente ao ambiente físico e material. Quando tratam da problemática qualitativa das relações, do serviço prestado como um tudo, ficam pouco definidas, genéricas e, muitas vezes idealizadas.

$\mathrm{Na}$ última (e fundamental) questão acerca do conhecimento METAS GERAIS do serviço e ESPECÍFICAS da área de atendimento 14 (quatorze, 70\%) pesoas não responderam. Incluimos nesse grupo uma pessoa que refere conhecer mas não descreve qual seja. Poucas pessoas portanto relataram conhecer as metas da instituição e área de trabalho : 06 (seis, 30\%).

Naquele período o serviço passava por reestruturação importantes devido às mudanças político-administrativas do Sistema de Saúde, estávamos em fase de implantação do SUDS no município e entre as transformações consequentes, destacamos a finalidade do próprio C.S.E., que ao lado de açōes de caráter preventivo passou a exercer a Atenção Primária à Saúde. Esta se refere à assistência dos problemas mais comuns de saúde da população, of erecendo atendimento em clínica médica, ginecologia, pediatria, odontologia, aplicação de vacinas, execução de tratamentos, curativos, reidratação oral, coleta de material : constitui o conjunto de ações promotoras e recuperadoras da saúde capazes de proporcionar 80 a $90 \%$ de resolutividade em relação aos problemas existentes na área de abrangência da unidade.

Paralelamente a esse processo a equipe técnica do serviço buscava a definição de metas concretas, passíveis de avaliação e acompanhamento.

Para melhor documentar este estudo anexamos algumas citações das respostas dos funcionários aos ítens do roteiro. Neste momento não pudemos contemplar uma análise pormenorizada dos mesmos, considerando que esta demanda estudos posteriores. (ANEXO 2)

\section{CONSIDERAÇÕES FINAIS}

Os funcionários e a instituição como um todo não dispunham, no momento da avaliação referida neste estudo de um projeto concreto de trabalho e atendimento à clientela. Os objetivos de trabalho na instituição, de forma genérica e abstrata pautavam-se na assistência à saúde da população, com bom desempenho técnico, qualidade e iniciativa do pessoal de enfermagem.

As instituições de saúde produzem serviços e não bens, o que já dificulta a avaliação. No C.S.E. as atividades não estavam concretamente definidas e expres- sas, portanto, não havia parâmetros ou critérios para avaliá-las, tornando mais difícil a tarefa proposta.

A elaboração deste estudo, acrescida das discussões com pessoas que participam do processo de trabalho no C.S.E., contribuiu para aprendermos o quanto nossas atividades, dentre elas a avaliação, são. fragmentadas. Estávamos ainda centradas nas questões formais, sem preocupação com os objetivos concretos que devem nortear a avaliação e possíveis propostas de mudança que possam advir.

Concluimos que sua contribuição está em que questionarmos a avaliação em si, passando a compreendê-la como parte do processo de trabalho como um todo, a partir de metas passíveis de verificação quantitativa e qualitativamente.

Não idealizamos que simplesmente conhecer a "fragmentação" do nosso trabalho faça com que esse se altere mecanicamente, mas ententemos que essa etapa de conscientização seja fundamental no sentido de possibilitar mudanças na nossa prática e consequentemente, a melhoria da qualidade da assistência de enfermagem.

\section{REFERÊNCIAS BIBLIOGRÁFICAS}

1 ALMEIDA, Maria Cećlia P. ROCHA, Juan S.Y. O saber de enfermagem e sua dimensão prática. São Paulo : Cortez, 1986, 128 p.

2 ALMEIDA, Maria Cecília P. Processo e divisão do trabalho na enfermagem. tema oficial do XXXIX Congresso Brasileiro de Enfermagem da ABEn, Salvador - BA, $1987.18 \mathrm{p}$.

3 BRAVERMAN, Harry. Trabalho e capital monopolista: a degradação do trabalko no século XX. trad. Nathanael C. Caixeiro, 3 ed. Rio de Janeiro, Guanabara, 1987. 379 p.

4 CONSELHO FEDERAL DE ENFERMAGEM/ASSOCIAÇĀO BRASILEIRA DE ENFERMAGEM. O exercicio da Enfermagem nas instituiçōes de saúde do Brasil: 1982 - 1983. COFEn/ABEn. Rio de Janeiro, 1985. v. 1. 236 p.

5 GERMANO, Raimunda Maria - Educação $e$ ideologia da Enfermagem no Brasil. São Paulo: Cortez, 1983. 118 p.

6 GONÇALVES, Ricardo Bruno M. Processo de trabalho em saúde. (mimeografado) s./d. 31 p.

7 MELO, Cristina Divisão social do trabalho e enfermagem. São Paulo: Cortez, 1986. 94 p.

8 OLIVEIRA, Maria Ivete R. Enfermagem e estrutura social. in: Anais do XXXI Congresso Brasileiro de Enfermagem. Fortaleza, 1979. p. 9 - 26

9 ROCHA, Semíramis Melani de M. IPuericultura e enfermagem. São Paulo: Cortez, 1987. 119 p.

10 RODRIGUES, Wanda W. TORRES, Valquíria R.' Contribuição ao desenvolvínento do processo de avaliação em serviços de saúde. Brasilia. Centro de Documentação do Ministério da Saúde, 1982. 46 p.

11 SILVA, Graciete B. A enfermagem profissional : análise. critica. São Paulo: Cortez, 1986. 143 p.

12 SILVA, Graciete B. et alli. IIntrodução à análise das transformaçōes na prática de enfermagem no Brasil, no perfodo 1920 - 1978. in Rev. MEDICINA HCFMRP USP e CARL 17 (1 e 2): 35-47, 1984. 


\section{DESEMPENHO TÉCNICO QUALITATIVO}

"Na triagem se eu não sei a área de abrangência do Centro de Saúde, devo procurar na listagem e não ficar perguntando para outra pessoa".

"Acho meu desempenho técnico bom, mas acho que com uma reciclagem ou rodízio das áreas os funcionários poderiam ser de maior qualidade do que é hoje".

\section{DESEMPENHO TÉCNICO QUANTITATIVO}

"Para mim não ficou claro esse ítem. Para mim responderei que a qualidade do serviço conta muito mais que a quantidade".

"Quanto à quantidade acho muito relativo pois nem sempre depende apenas de um funcionário para aparecer quantidade. Acho que deveria ter oportunidade e maior espaço para poder juntar a quantidade à qualidade".

\section{FREQÜÊNCIA E PONTUALIDADE}

"Acredito ser uma funcionária constante no serviço e pontual. Eventualmente chego atrasada, e quando acontece é problema de atraso de ônibus".

"Sou frequente e pontual, a menos que aconteça eventualidades, mesmo assim procuro comunicar a tempo que outra pessoa possa me cobrir".

\section{ORGANIZAÇÃO DO MÉTOdO DE TRABA- LHO}

"Hå muitas falhas na organização de gavetas e papéis, que deve ser discutido entre as colegas para melhor aproveitamento do espaço e do material que dispomos".

"Procuro sempre aprender e me orientar antes de começar qualquer trabalho, procuro reunir o máximo de informações para começar qualquer que se ja o trabalho".

\section{ORGANIZAÇÃO DO MATERIAL DE TRA- BALHO}

"Tem sido boa mas pode melhorar em alguns aspectos, como na organização de material do trabalho e previsão de material".

\section{ORGANIZAÇÃO DO TEMPO DAS ATIVI- DADES}

"Nos grupos é colocado horário de uma hora de duração para não ser cansativo, agora no atendimento do dia-a-dia torna-se difícil, pois vou depender do número de pacientes a ser atendidos e da capacidade de entendimento de cada um".

"O tempo a gente faz (organizar) conforme a ociosidade de alguma área".

"Acho muito relativo, pois nem sempre o que faço hoje poderá ser repetido no dia seguinte igual, mas procuro sempre organizar e desempenhar a minha proposta de serviço em tempo determinado".

\section{COOPERAÇÃO}

"Colaborando com todos os colegas de trabalho, inclusive alunos e residentes para que tenham condições de desempenhar suas funções da melhor maneira possível, para formarmos uma equipe coesa e funcional".

"Sempre que estou disponível e vejo algum colega de serviço em outra área (apertado) vou ajudá-lo."

"Quanto a mim quando estou apertada na minha área não me sinto à vontade para pedir ajuda com receio de ouvir um não e também porque acho que $c$ meu colega é que deveria se oferecer para ajudar".

"Na medida do possível procuro cooperar com aqueles que necessitam de minha ajuda seja com trabalhos ou palavras, com os pacientes também procuro, agir da mesma forma. Há alguns meses atrás eu não sabia pedir ajuda, mas agora comecei a pedir quando, estou necessitada".

"Procuro sempre cooperar com os colegas às ve-. zes me excedendo além do meu limite, mas estou pro.. curando dividir mais o trabalho para dar melhor de.. sempenho, orientação, ter calma e tolerância com os nossos pacientes, que na maioria são muitos carentes, principalmente de informação."

\section{ENTROSAMENTO}

"Sinceramente acho que preciso aprender a me soltar um pouco mais, pois muitas vezes eu tenho receio de ser inoportuna e com isso acho que estou per-. dendo algo que poderia aprender ou a ser mais presta-tiva".

\section{ENTROSAMENTO COM FUNCIONÁRIOS}

"Procuro me relacionar bem com todos, pois acredito que o bom andamento do serviço depende muito do bom relacionamento entre os funcionários".

"Gosto de minhas colegas de trabalho, apesar de diferentes opiniões, manias, costumes. Apesar de que, deveríamos todos ter o mesmo ideal em relação ao serviço, pois temos por dever um mesmo objetivo. Considero muito importante um bom relacionament() com quem quer que seja. Nos não somos sozinhos -dependemos de pessoas e coisas".

\section{ENTROSAMENTO COM PACIENTES}

"Procuro me entrosar bem com os mesmos pois acredito que a maneira como recebemos o paciente, ajuda muito para que ele se sinta a vontade".

\section{ENTROSAMENTO COM ALUNOS E RESI- DENTES}

"As vezes me sinto intimidada e pouco à vontade com a presença deles, pois alguns chegam ao serviço numa atitude de que eles tem o conhecimento e nós, s 6 tocamos o serviço. Mas acho que o serviço e nós temos muito a ganhar com a presença deles pois há troca de experiências, provoca discussões e estimula o aprendizado". 


\section{INICIATIVA NAS ATIVIDADES}

"Procuro organizar as atividades da minha área de um modo que estejam em ordem para facilitar o meu trabalho e o trabalho das pessoas que trabalham comigo, providenciando materiais de uso de minha área que este jam em falta".

"Tenho boa inciativa principalmente em relação à triagem na pediatria e quanto à pós-consulta".

\section{INICIATIVA NA APRENDIZAGEM}

"Quanto à aprendizagem procuro fazer leituras de assuntos relacionados com as áreas que trabalho, e também, de assuntos relacionados a outras áreas quando possível fazendo discussões dos mesmos".

"Além de procurar aprender mais sobre a Enfermagem, procuro aprender uma das coisas mais importantes: o ter melhor relação entre trabalho de equipe, para com os colegas de trabalhos, e ao próprio serviço que me é estipulado".

\section{DISPONBILIDADE}

"Me considero uma funcionária disponível para o trabalho pois se precisar que eu fique além do meu horário eu fico".

"Boa, estou sempre disposto a cooperar para cobrir colegas de outras áreas de acordo com a necessidade do serviço".

"Tenho disponibilidade quanto (ao) horário de trabalho, e qualquer mudança sempre que avisada com antecedência (para providenciar algumas particulares tais como filhos, casa, etc. ).

\section{ÇOS \\ AVALIAÇÃO DA ESTRUTURA DO SERVI-}

"Acredito que o pessoal deveria ter treinamento psicologico e de relações humanas para se ter um melhor relacionamento entre os colegas de trabalho e com os pacientes.

Acho também que deveria ter mensalmente ou bimestralmente um treinamento em todas as áreas para que o pessoal estivesse sempre atualizado quanto a novos métodos de tratamento ou mesmo para tirar dúvidas que surgem no dia-a-dia, mesmo que tivéssemos que diminuir o número de atendimentos no dia do treinamento, pois acho que seria importante para que o nosso serviço tivesse uma boa qualidade".

“às vezes em serviço não pode ser feito por falta de material ou pessoas capacitadas para fazê-lo, acho que temos que nos organizarmos melhor para que isso não aconteça. É preciso que nós enquanto funcionários da saúde tenhamos consciência da importância do nosso trabalho, responsabilidade e compromisso para com a população que atendemos. Precisamos ter como objetivo o melhor atendimento possível ao paciente, sem fazê-lo esperar ou andar desnecessariamente".

"Nenhum serviço é perfeito. Sempre há falhas, no caso causadas pelos que o compõem. Existe falta de materiais e também de condições para um melhor desempenho. Mas a tarefa sempre deve ser cumprida além e apesar de".

"Acho que deveria a limpeza ser mais caprichada, pois o serviço é utilizado para todos os casos de doenças".
"Ultimamente tenho percebido que o serviço sofreu várias transformações, acho que até foi bom, mas o serviço mudou, a forma de trabalhar mudou, mas a falta de condições de trabalho continua a mesma. É difícil trabalhar ou melhorar a qualidade do mesmo. com tanta falta de materiais, medicações, papéis etc. Acho que falta um pouco de interesse por parte de certos funcionários também".

\section{SUGESTŌES}

"Existe um período no serviço que deveria ser preenchido com coisas desse tipo (cursos, treinamentos). Melhoraria a qualidade de atendimento e evitaria a ociosidade consequente das oito horas, que acaba levando funcionários a situações desagradáveis. Com isso teria também um maior aproveitamento do potencial de cada indivíduo".

"Acho que deveria ser mais distribuidas as tarefas e muito interessante o rodízio de funcionários, os que estão menos atarefados procurar reciclar e se interar do que é saúde e como trabalhar em grupo".

"Eu não sei o que pode ser feito para melhorar o serviço que prestamos, talvez um caminho se ja discutirmos entre nós nossas dificuldades e ouvirmos o que cada um pensa, para a partir daí sim surgirem algumas sugestões".

"Que nos períodos de ociosidade deste serviço se formem grupos de estudo com os colegas de trabalho".

"É que se pense um pouco mais na qualidade e não tanto na quantidade. Sei que os números são importantes, porém existem áreas como por exemplo a Tisiologia e a Dermatologia que hoje estão meio misturadas e confusas, sendo que elas sempre foram áreas consideradas importantíssimas pelos seus programas de $\mathrm{Tb}$. e $\mathrm{MH}$.. Acho que com as 8 horas podemos separar um pouco melhor as áreas para melhor atender os pacientes".

"Acho que deveria ser permitido aos funcionários o direito de ser ouvido, às vezes isso não acontece, mais recurso para por em prática o trabalho e maior credibilidade".

"Minha sugestão é o uso do jaleco, e tentativa de organizar pedidos de materiais para que não chegue a faltar".

\section{METAS EM RELAÇÃO ÀS DEFICIÊNCIAS ENCONTRADAS}

“Os objetivos: melhorar principalmente os registros e cooperar mais para algum tipo de pesquisa na área, e que posso participar de algum trabalho de grupo".

"Quando comecei a escrever esta avaliação tinha coisas que até então eu não havia percebido tais como: roupas que uso para trabalhar, organização do meu trabalho (tempo previsto para atividades), registro de reuniões. Vou tentar prestar mais atenção a esses pontos para que não voltem a acontecer".

"Iniciar o uso de avental. Fazer uma previsão de materiais que necessitam, as respectivas áreas em que trabalho, este processo ocorreria uma vez por semana com o preparo de uma lista a ser entregue na farmácia deste serviço. Quando ir às reuniões, comparecer munida de papel e caneta". 
"Melhor entrosamento e colaboração entre col gas, atenção máxima com checagem de fichas e prontuários e sigilo quanto as pessoas que procuram o serviço".

\section{OBJETIVOS DA ÁREA E DO CSE}

"Receio que não (conheço) tão bem quanto gostaria e deveria. Creio que aumentar o serviço especializado e o número de atendimentos. Educação familiar e sanitária através dos pós-consultas e dos grupos, melhor atendimento qualitativo e quantitativo".

"Prestar assistência médica à população, dar apoio à pesquisa e receber aluno para estágio colaborando assim para formação de novos profissionais. Na área: controle das doenças transmíssiveis, isso implica na obtenção de dados corretos, controle de comunicantes, conhecimento de como vários fatores interferem no agravamento, transmissão e disposição das doenças na população".

"Trazer para este serviço (oftalmologia) a população mais carente, que se encontram um pouco distante. É desenvolver (na psicologia) trabalho de grupo em geral, (na psiquiatria) ainda não tenho claro quais são os objetivos e metas".

"Aperfeiçoamento para um melhor atendimento".

"É atender as áreas abrangentes, tanto no tratamento preventivo como no tratamento curativo, nas demais clínicas de atendimento. Quanto à meta da sala de vacinas: imunizar os pacientes (crianças e adultos), ajudar no diagnóstico das doenças como $\mathrm{Tb}$ e $\mathrm{MH}$ (com testes de sensibilidade)".

\section{ASSOCIE-SE A ABEn NO SEU ESTADO}

